\title{
The Emerging Theoretical Framework of Life Course Health Development
}

\author{
Neal Halfon and Christopher B. Forrest
}

\section{Part 1: Context and Background}

Over the last century, we have witnessed the power of the biomedical paradigm to treat the sick and prevent diseases from occurring. Conventional health science, as an applied field, has tried to make sense of what constitutes health by exploring the causes of disease in individual patients (medicine) and populations (public health). This approach has created a perspective of health as absence of disease or its risk factors and has been unsuccessful at explaining what it means to be healthy, how health develops over the lifespan, and the impact of health on the lives of individuals.

\footnotetext{
N. Halfon, MD, MPH ( $₫)$

Department of Pediatrics, David Geffen School of Medicine, UCLA, Los Angeles, CA, USA

Department of Health Policy and Management, Fielding School of Public Health, UCLA, Los Angeles, CA, USA
}

Department of Public Policy, Luskin School of Public Affairs, UCLA, Los Angeles, CA, USA

Center for Healthier Children, Families, and

Communities, UCLA, Los Angeles, CA, USA

e-mail: nhalfon@ucla.edu

C.B. Forrest, MD, PhD

Applied Clinical Research Center, Children's Hospital of Philadelphia, Philadelphia, PA, USA
Concepts of what constitutes health, and theories about how health is produced and optimized, are constantly evolving in response to myriad social and cultural expectations shaped by our contemporary worldview, scientific advances, improvements in health interventions, and the changing capacity of the health system. Stimulated originally by a series of studies demonstrating how growth during early life is related to chronic health conditions that emerge many decades later, an eruption of new research is identifying developmental processes that shape long-term health trajectories (Ben-Shlomo and Kuh 2002; Kuh and Ben-Shlomo 2004; Hanson and Gluckman 2014). This research is demonstrating how complex developmental processes integrate a range of behavioral, social, and environmental influences that modify gene expression, modulate physiologic and behavioral function, and dynamically shape different pathways of health production (Halfon and Hochstein 2002; Kuh and BenShlomo 2004; Halfon et al. 2014). These empirical findings are highlighting the limitations of the more mechanistic biomedical and biopsychosocial models of health, which fail to offer comprehensive explanations about such phenomena as the developmental origins of health, how stress affects current and future health, and the consequences of dynamic interactions between individuals and their environments over time.

Informed by new theoretical perspectives emerging from such fields of study as developmental 
psychology (Lerner 2012), systems biology (Kitano 2002; Antony et al. 2012; Schadt and Bjorkegren 2012), epigenetics (Egger et al. 2004), the developmental origins of chronic disease (Gluckman and Hanson 2006a), and evolutionary developmental biology (West-Eberhard 2003), a transdisciplinary framework (Gatzweller and Baumuller 2013) is emerging which we call Life Course Health Development (LCHD) (Halfon and Hochstein 2002, Halfon et al. 2014). As a framework, LCHD organizes several different theories and conceptual models in order to make sense of the enormously challenging question of how health develops over the lifespan.

The LCHD framework addresses the developmental origins of health, the role that biological and behavioral plasticity play in facilitating different levels of adaptation, and how mismatches between biological propensity and environmental context interact to produce breakdowns in health, known as disease. As a framework that organizes numerous theories and concepts related to how health develops, LCHD is bridging what have sometimes been assumed to be polar opposites: nature versus nurture, mind versus body, individual versus population, and short-term versus long-term change. By unifying these dichotomies, LCHD offers a new perspective that will guide future scientific inquiry on health development and facilitate a long overdue and needed synthesis of medicine and public health - a synthesis that links treatment, prevention, and health promotion and catalyzes more integrated and networked strategies for designing, organizing, and implementing multilevel health interventions that transcend individual and population dichotomies. The LCHD framework will be increasingly useful as the human ecological footprint expands and influences the health development of Earth itself, creating new threats to human health via rapid and disruptive changes in physical environments, geographic dispersion of populations, and changes in social development.

This emergence of LCHD is reflective of larger scientific trends that are transforming research in the physical, natural, and social sciences. The comfort and certainty of simple, linear, and deterministic causal pathways are giving way to the uncomfortable uncertainty of nonlinear causal clusters that are networked together into complex, multilevel, interactive, and relational systems. LCHD embraces this complexity as the salient target of inquiry and requires research to be conducted with teams that are multidisciplinary, often large, networked, and highly collaborative. These shifts in scientific approach are helping us understand how our modern interdependent world is organized, how it functions, and how it contributes to the production of human health.

Given the explosion of life course-focused research in many scientific fields-including chronic disease epidemiology, developmental neuroscience, developmental psychology, evolutionary biology, genetics, epigenetics, environmental health sciences, economics, sociology, and many more - there is a growing need to provide a systematic framework for understanding and organizing this emerging knowledge base (i.e., sense making) so that it can be more effectively applied to solving health problems and guiding new and productive streams of exploration and discovery.

Our intent is not to provide a grand theory of Life Course Health Development. Rather, we seek to establish a set of principles that describe the contours of the rapidly emerging health development knowledge base by organizing many theories and conceptual models into a coherent synthesis. We recognize that LCHD is a work in progress. Our aim is to create conceptual coherence by contextualizing the meaning of disparate research findings, identifying gaps and uncertainties - including how concepts are defined, operationalized, and interpreted-and moving inquiry, application, and implementation forward. We hope that the principles of LCHD presented here, coupled with our explanatory narrative, will encourage theory building and testing, inspire innovative transdisciplinary research, and mature the framework into a scientific model with descriptive, explanatory, and predictive utility. Furthermore, we hope that LCHD will shine a light on the conundrum of how little attributable risk is explained in many studies of chronic disease, how early experience conditions future biological response patterns, and how these early 
experiences play through complex, environmentally influenced, and developmentally plastic health development pathways (Table 1).

In Part 2 of this chapter, we describe the ontological pathways-including theories, empirical findings, and concepts - that led to the LCHD framework, thereby orienting our view of health development from simple, mechanistic, and reductionist models to contemporary models that are holistic, complex, dynamically relational, and adaptive. In Part 3, we summarize the principles of the LCHD framework, grounding them in a set of transdisciplinary theories, models, and perspectives and addressing their implications for future inquiry (Fig. 1).

Beginning with the simple, mechanical, and mostly linear biomedical model, we chart how it was transformed into a more hierarchical,

Table 1 Principles of the Life Course Health Development Framework

\begin{tabular}{l|l}
\hline Principle & Brief description \\
\hline Development & $\begin{array}{l}\text { Health development integrates the } \\
\text { concepts of health and developmental } \\
\text { processes into a unified whole }\end{array}$ \\
\hline 2. Unfolding & $\begin{array}{l}\text { Health development unfolds } \\
\text { continuously over the lifespan, from } \\
\text { conception to death, and is shaped by } \\
\text { prior experiences and environmental } \\
\text { interactions }\end{array}$ \\
\hline 3. Complexity & $\begin{array}{l}\text { Health development results from } \\
\text { adaptive, multilevel, and reciprocal } \\
\text { interactions between individuals and } \\
\text { their physical, natural, and social } \\
\text { environments }\end{array}$ \\
\hline 4. Timing & $\begin{array}{l}\text { Health development is sensitive to } \\
\text { the timing and social structuring of } \\
\text { environmental exposures and } \\
\text { experiences }\end{array}$ \\
\hline 5. Thriving & $\begin{array}{l}\text { Health development phenotypes are } \\
\text { systematically malleable and enabled } \\
\text { and constrained by evolution to } \\
\text { enhance adaptability to diverse } \\
\text { environments }\end{array}$ \\
\hline $\begin{array}{l}\text { Optimal health development } \\
\text { promotes survival, enhances } \\
\text { well-being, and protects against } \\
\text { disease }\end{array}$ \\
\hline $\begin{array}{l}\text { Health development results from the } \\
\text { balanced interactions of molecular, } \\
\text { physiological, behavioral, cultural, } \\
\text { and evolutionary processes }\end{array}$ \\
\hline Farmony
\end{tabular}

dynamic, and multiply determined biopsychosocial model, as the result of scientific breakthroughs in the understanding of the contribution of behavioral, social factors and their influence on individuals during specific life stages. This biopsychosocial model has now evolved into a more complex, relational, adaptive, dynamic, and developmental model of Life Course Health Development (LCHD) as result of the influence of scientific breakthroughs in epigenetics, neurodevelopment, and life course chronic disease epidemiology.

\section{$2 \quad$ Part 2: Emergence of the Life Course Health Development Framework}

The LCHD framework has emerged from a network of theories, conceptual models, and empirical findings and provides a more comprehensive description of how health develops over the life course than any single component part. In this section, we describe the streams of scientific inquiry, the key theories and models, and the seminal scientific insights that are brought together by the LCHD framework. Figure 1 provides an epistemological schematic, charting the changing paradigms of health and how different streams of research and their findings influenced the flow of conceptual models.

A few decades ago, research linked fetal development with degenerative diseases of old age (Ben-Shlomo and Kuh 2002), stimulating new ways of thinking about the mechanisms underlying what was originally termed "fetal programming" and other environmentally induced modifications in gene expression that presumably take place early in life. These insights pointed out the need to better characterize interactions between genes and the environment, to better understand gene regulation that occurs in response to environmental signal transduction, and to better integrate into explanatory models the importance of the timing and phasing of these developmental processes. The prevailing epidemiological framework, with its simple additive, exposure-response models of risk accumulation 


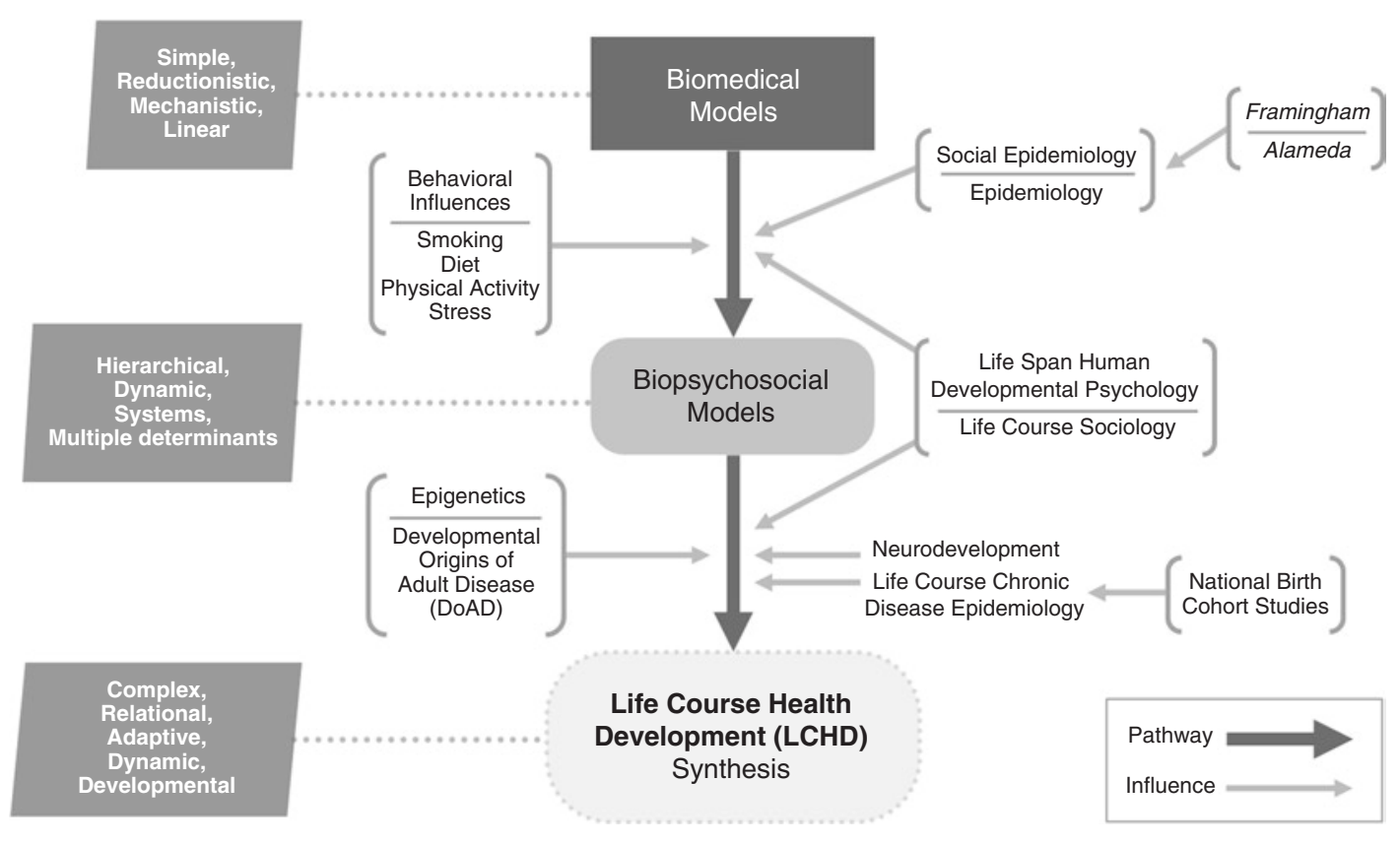

Fig. 1 The evolution of conceptual models of health development

as the etiology for chronic disease in adult life, could not satisfactorily explain these more complex time-dependent phenomena. Instead, a theoretical framework was needed to explain the processes of translating an individual's experiences and exposures into the development of health over the life course.

Two converging streams of biological research and conceptual constructs have contributed to the LCHD framework. The first stream represents the basic biology of human development, informed by the neo-Darwinian synthesis that resulted from the convergence of Darwin's theory of evolution and Mendel's notion of genes as the building blocks of heredity. Although the central dogma of "genes/DNA $\rightarrow$ mRNA $\rightarrow$ proteins" has served as a foundational construct for modern molecular biology, it led to overly deterministic genotype-to-phenotype models (Huang 2012). Recent advances in panomics (e.g., genomics, epigenomics, proteomics, metabolomics) and systems biology are redefining our understanding of how gene networks are regulated and dynamically interact with each other and the environment, resulting in a new synthesis of biological systems development and function- ing (Huang 2012; Forrest 2014; Davila-Velderrain et al. 2015). Breakthroughs in understanding the relationships between evolutionary processes and biological development, and advances in the use of life history theory to explain how mismatches between biological propensities and modern environments influence the onset of disease, have also provided a new way of considering the relationship of an individual's or a population's genetic endowment and the phenotypes that emerge (Del Giudice et al. 2015; Green et al. 2015; Hanson and Gluckman 2014; Lieberman 2014; Gluckman and Hanson 2006a).

The second stream of inquiry, which interacted with genetic concepts and models, represents the evolution of models of disease causation, informed by contributions from basic, clinical, epidemiologic, social, and psychological research disciplines. In the first era of health science, scientific methods applied to medicine resulted in the development of a biomedical framework in which anatomical-pathological disease models, along with other mechanistic constructs, were used to explain why disease develops. One prototypical theoretical construct was germ theory (i.e., germs as the unique causes of infectious dis- 
eases) (Stewart 1968). Others included theories of inheritance that were informed by simple and mechanistic notions of genes as the unique causes of inherited disorders and risk status. Several decades of research on the "upstream" social and behavioral determinants of health were stimulated by epidemiologic studies like the Framingham Study and Alameda County Study that highlighted how cardiovascular and other chronic diseases were not caused by bad germs, bad genes, or bad luck, but were related to behaviors like smoking, diet, exercise, and other social factors as well as the metabolic changes that these social and behavioral risk factors induced (Dawber et al. 1974; Haynes 1980; Berkman and Syme 1979). This led to a more dynamic ecological analysis of the multiple risk factors that lead to disease causation, informing the creation of a multi-causal, biopsychosocial framework of disease (Engel 1977). Over the last 20 years, this biopsychosocial model of health has continued to evolve as a result of the integration of concepts from life course research in sociology (Elder 1995; Elder and Shanahan 2007), lifespan developmental research in psychology (Lerner 2012), systems biology (Schadt and Bjorkegren 2012), and longitudinal studies on the origins of chronic disease (Gluckman and Hanson 2004b). The biopsychosocial model undergirds much of the current focus on the social determinants of health and the important role that contextual factors play in shaping health outcomes (McMichael 1999; Krieger 2001).

Midway through the twentieth century, social scientists started examining how the rapidly changing social circumstances of the second industrial revolution were transforming the developmental pathways of different generations. Separate yet related streams of research emerged, converging around notions of the life course, the lifespan, and the human life cycle development. Two lines of investigation in particular have informed recent notions of health development: life course sociology and lifespan human developmental psychology (Diewald and Mayer 2009).

Life course theories emerged in sociology research in the 1960s, championed by Elder, Clausen, and others. These theories distinguished how social institutions and history shape the roles, personal events, transitions, and trajectories of individuals who follow different developmental pathways (Clausen 1986; Elder et al. 2003). Macro-level social processes and social relationships influence interweaving trajectories at different ages, stages, and transitions of development (Elder 1995). Untangling age, period, and cohort effects and understanding the cumulative impact of experience on socially and institutionally constructed life pathways form the basis of life course sociology. For example, the experience of low socioeconomic status, discrimination, and racial segregation may have different effects on health for different cohorts (i.e., groups born at different times), based on prevailing (period effects), compensatory, and mediating factors such as the availability of healthcare or the impact of different social policies (Chen et al. 2010; Masters et al. 2012).

Building on the work of Glen Elder, Duane Alwin (2012) suggested five ways that the term "life course" was used to describe etiologic processes in social and behavioral sciences: (1) lifespan development, humans develop over the life course; (2) agency, individuals construct their lives through choices and actions they take within social structures that provide opportunities and impose constraints; (3) cohort and geographic variation, lives of individuals are embedded and shaped by historical time and place where they live; (4) timing, impact of events, experiences, and transitions are conditional on their timing in a person's life; and, (5) linked lives, people's lives are lived interdependently (e.g., husband and wife, siblings).

Lifespan human developmental psychologists attempt to explain how individual differences emerge at different ages and stages (Lerner 1984; Lerner 2012). These differences are, in part, determined by endogenous characteristics (i.e., each individual's personal adaptability, plasticity, resilience, and reactivity) interacting with exogenous factors (i.e., external physical, social, and psychological environments that promote adaptation). These interactions cause human behavior to continuously change from conception to death (Lerner 1984, 2012). By focusing on the individ- 
ual's capacity to adapt to events and experiences (Dannefer 1984; Alwin 2012), developmental psychologists have suggested that lifespan human development research concentrates on the plasticity associated with individual development (ontogenesis), whereas life course social sciences researchers emphasize "sociogenesis" or how life pathways are informed and structured by socially constructed developmental scaffolding and constraints. In short, psychologists have tended to focus on how endogenous or constitutional ontogenetic processes influence lifelong developmental trajectories, while sociologists have been more concerned with contextual or exogenous factors.

Over the past 30 years, there has growing convergence between life course sociology and lifespan human developmental psychology. Research on "linked lives," where the common and differential impact of shared exposures is experienced by individuals whose lives are linked geographically or socially (e.g., spouses, workers in a town, friendship networks) and work on transitions and turning points that are biologically (menarche, menopause) or socially determined (e.g., transitions from preschool to kindergarten, school to work, work to retirement), have each benefited from consideration of endogenous and exogenous factors. As the sociological approaches to life course and psychological approaches to lifespan research converge into a more integrated discipline of developmental science (Cairns et al. 1996; Bornstein and Lamb 2005; Diewald and Mayer 2009), ongoing conceptual and empirical integration is increasingly influenced by the study of nonlinear dynamic systems, including complex adaptive systems theory (Greenberg and Partridge 2010).

Many researchers and thought leaders have contributed to the conceptual evolution and empirical evidence supporting a more integrated developmental systems theory (Sameroff 1975; Bronfenbrenner 1976; Baltes et al. 1980; Lerner 1984; Cicchetti and Cohen 1995; Magnusson 1995; Cairns et al. 1996; Bronfenbrenner and Morris 2006; Sameroff 2010) which built upon earlier behavioral and biological theories (Greenberg and Partridge 2010; Marshall 2014).
Overton and Lerner have proposed a theoretical construct that they call "relational developmental systems theory (RDST)” (Lerner 2006; Lerner and Overton 2008). Rejecting what they consider a false dichotomy between individual and context, they suggest that a person's development is embedded in, organized by, and co-regulated by his or her surrounding environments. Developmental regulatory functions are best understood as mutually influential, bidirectional, person-context interactions. RDST sees individuals as active co-developers of their own developmental pathways, adaptively responding to different biological, social, cultural, and physical environmental contexts that they influence and are also influenced by. RDST has been used as a theoretical foundation for research on selfregulation and positive youth development and has added a stronger relational dimension to life course thinking.

Like the converging influences of life course sociology and lifespan human developmental psychology, many fields of the life sciences have also informed this transition toward a life course developmental view of health. Embryologists and teratologists in the first part of the twentieth century understood that environmental insults could disrupt the normal processes of development leading to malformation and other "genetic" abnormalities, and some scientists began to consider how childhood conditions might directly influence adult mortality (Kuh and Davey Smith 2004). But it was not until the 1970s-when Forsdahl suggested a relationship between childhood socioeconomic status and later cardiovascular disease, Barker studied the relationship between birth weight and cardiovascular disease, and Wadsworth observed that other early childhood factors influenced a range of adult health outcomes - that a focus on what is called the developmental origins of adult health and disease (DOHaD) began to emerge (Forsdahl 1977; Arnesen and Forsdahl 1985; Barker et al. 1989a,b; Kuh and Wadsworth 1993).

The receptivity to this new perspective was heightened by a growing number of challenges to the biomedical model of causation. Echoing George Engel and others, social epidemiologists 
like John Cassel, Leonard Syme, Lisa Berkman, and Michael Marmot and health service researchers like Barbara Starfield began to adopt a more complex, multidimensional "web of causation" construct to explain the origins of disease (Cassel 1964; Starfield 1973; Starfield et al. 1984; Marmot and Syme 1976; Syme and Berkman 1976; Marmot et al. 1978a, b). At the same time, a growing body of new research in psychoneuroimmunology described the "embodiment of disease risk" by demonstrating how different social, cultural, and psychological exposures quite literally "get under the skin" and are encoded or embedded into developing biobehavioral systems (Sapolsky et al. 1985; Maier et al. 1994; Cohen and Herbert 1996; McEwan 1998; Repetti et al. 2002).

Over the past two decades, the Barker hypothesis, as it was commonly referred to, was further elaborated by a series of studies examining the impact of birth weight, fetal growth, placental size, and weight gain in the first year of life on metabolic regulation and cardiovascular disease (Barker et al. 1989a,b, 1993; McMillen and Robinson 2005; Barker et al. 2010). An entire field of life course epidemiology was spawned that has not only confirmed Barker's findings in several other cohorts and settings but vastly expanded the empirical base linking fetal and early childhood growth and nutrition to a growing array of adult health conditions. This work has also gone beyond examining fetal and early childhood origins to explore the developmental origins of health and disease more broadly and has generated various conceptual models to analyze and synthesize results (Schlotz and Phillips 2009; Gluckman et al. 2010; Entringer et al. 2012). A new generation of recent epigenetic studies have begun to provide a stronger biological and theoretical basis for understanding how developmental plasticity is manifested, how gene expression may be modified in response to environmental cues, and how biological and behavioral traits can be perpetuated across multiple generations (Hochberg et al. 2010; Gluckman 2014; Thayer and Kuzawa 2011; Davey Smith 2012; Lillycrop and Burdge 2012; Relton and Davey Smith 2012; Gilbert et al. 2015; Cunliffe 2015).
Complementary studies of the developing brain demonstrated how stress and social adversity influence the biology of human development during sensitive periods (Hertzman 1999; Boyce et al. 2012; Hertzman 2012). Building on earlier studies of experience-dependent and experienceexpectant ${ }^{1}$ neuronal development, neurodevelopmental research demonstrated how development is guided by the combined and interactive influences of genes and experience (Boyce et al. 2012). Animal models of experience-modified neural development demonstrated how early behavioral experiences of adversity or comfort can lead to different DNA methylation patterns, which are believed to affect gene regulation and result in different functional levels of neurotransmission capacity (Meaney 2001; Szyf et al. 2005; Meaney et al. 2007). Similar methylation alterations have been demonstrated in children who have experienced adversity associated with maternal stress in the early years (Essex et al. 2011). Research on the neurobiology of stress and on the role that cumulative physiologic stress can have on the function of neuroendocrine and neuroimmunologic pathways has provided direct evidence for how exposure to risk and/or highly adverse environments is embedded in lifelong biobehavioral function (Seeman 1997; McEwan 1998; Seeman et al. 2001; Repetti et al. 2011; McEwen 2012). This research on neural development, stress, and biological priming provides an important empirical and conceptual bridge between observed social gradients in health and the experience-dependent conditioning of biobe-

\footnotetext{
${ }^{1}$ Experience-dependent neuronal development refers to the role that experience plays in fortifying neuronal connections (e.g., a violin player who shows increased synaptic density in the area of the brain corresponding to the motor cortex controlling the fingers, or the hypertrophy of hippocampus in London cab drivers that is associated with improved spatial navigation and spatial memory). Experience-expectant neuronal development refers to brain development that is contingent on experiences that are expected to occur as part of normal development. For example, typical development of the visual cortex occurs in response to visual stimuli that are available in everyday life. If vision is obstructed and the brain does not receive these expected stimuli, the relevant synapses will either not form or will atrophy.
} 
havioral systems that occurs during the process of human development (Hertzman 1999; Keating and Hertzman 1999; Halfon and Hochstein 2002).

In several ways, the converging relationship between life course chronic disease epidemiology, neurodevelopmental, and $\mathrm{DOHaD}$ research is analogous to the converging relationship between life course sociology and lifespan human developmental psychology. DOHaD and neurodevelopmental research have focused more on the individual differences in developmental plasticity from early development through old age (ontogenesis), leading to a growing understanding that epigenetic factors influence nongermline heredity. For example, the exposures grandparents experience can influence adaptive responses two generations later. In contrast, life course chronic disease epidemiology has focused more on social class, social gradients, and the social scaffolding of exposures (sociogenesis). New longitudinal cohort studies integrate both perspectives, including not only measures of phenotype but also genetic, epigenetic, and other biobehavioral adaptations (Alfred et al. 2012; Borghol et al. 2012; Elks et al. 2012).

\section{$3 \quad$ Part 3: Principles of the Life Course Health Development Framework}

In this section, we present the seven principles of the Life Course Health Development framework that emerged from our analysis of the network of theories, concepts, models, and research findings related to how health develops over the life course.

Each principle is described, connected to relevant theories, models, and perspectives, and discussed in terms of its implications for future research. Together, the principles constitute the LCHD framework, which is proposed as a way of systematically organizing the breadth of theories and conceptual models that help to explain and predict empirical findings on the production of health and disease causation over the life course.

\section{$4 \quad$ Principle 1: Health Development}

\subsection{What We Mean by "Health Development"}

Health development integrates the concepts of health and developmental processes into a unified whole.

We use the term "health development" to signify the framework's central focus, which is the linkage of health and development into a single construct. Health is often understood as a set of instrumental attributes that are employed when individuals pursue goal-directed behavior (Richman 2004; Forrest 2014). These attributes can be thought of as "assets" that are desirable, acquired, optimized, and maintained during the life course, enabling growth of an individual, survival, and adaptation to manifold environments. Examples of health assets that emerge at the level of an individual include motor function (capacity for movement), emotional regulation (capacity to manage emotions during challenges or stressful events), and cognitive function (capacity to perceive, process, and act on information leading to the acquisition of knowledge).

Development, in this context, refers to the processes by which health attributes change (i.e., mature, weather, degrade) during the lifespan. If health is a set of attributes that emerge at the level of the whole individual, development refers to the evolutionarily informed processes by which these attributes enable adaptation to changing social-environmental conditions. Health is the "what" (i.e., what changes) and development is the "how" (i.e., how health attributes change over time) of health development.

As an expression of an organism's livingness and essential adaptive nature, health development is an emergent property of a living system (Forrest 2014). Importantly, because this principle combines both health and development, it blends a temporal dimension into our conceptualization of human health. Health development has time-dependent and transactional connotations and is therefore dynamic. 
The health development of an individual at the level of "self" cannot be understood by isolating the biological function (or dysfunction) of an organ system or a particular behavior of an individual-although of course these subsystems have their own unique health development trajectories. The health development of an individual is comprised of an integrated set of capacities that dynamically mature and are involved in managing energy flows; processing and acting on information; recovering from, adapting to, and growing with environmental challenges; learning and forming capabilities; and producing offspring (Forrest 2014). Health development is a life course-informed phenomenon that results from transactions between the organism and its internal (i.e., gene, panomic, organ system, and physiologic networks) and external environments (i.e., family, social, cultural, and physical networks and environments).

\subsection{Theories and Frameworks Relevant to Health Development}

This principle combines a rich set of theories and conceptual frameworks related to health and development. Conceptualizing health development as an emergent property of an organism differs from earlier linear and reductionistic biomedical models of health and even from multilevel biopsychosocial models. It also sets the stage for considering health development as complex adaptive processes that emerge from living systems interacting with their environments. Its relational ontology implies that other principles contribute to the understanding of this complex emergent process.

The optimization of health development is codependent on several contributing developmental processes and resulting propensities that are highlighted in the other LCHD principles and drawn from relational developmental systems theory (Lerner 2006; Overton 2007), developmental systems theory (Oyama 1985), dynamic systems theory (Spencer et al. 2009), and the unified theory of development (Sameroff 2010).

\subsection{Implications of the Health Development Principle}

The health development principle signals the importance of context and our inability to reduce health to its component parts divorced from the contexts within which they develop. This type of developmental systems thinking requires new typologies to describe health development phenotypes. In effect, a new set of concepts is needed to convey a language of health development as observed and experienced at the level of whole persons in dynamic interaction with their environments. As our understanding of the interrelationships between health development and a range of influential environmental variables matures, health development typologies can become fullfledged ontologies that help explain and predict which relational influences are important and have measurable consequences on health development.

The creation of "whole person" health development metrics that operationalize health development concepts is necessary to capture developmentally influenced continuity, consistency, and variability. To distinguish "health development" from other fields in the developmental sciences, we will need to specify the unique concepts that constitute it and the measures that assess health development's multidimensional functionality (adaptation, energy management, reproduction, information processing, capacity to execute tasks in response, and restoration and their integration) as well as its multilevel (from the molecular to the individual to the environmental) nature. Measures of health development will also need to be informed and reflective of the other LCHD principles outlined below. Such measures will be particularly important in enabling and measuring the contribution of health-producing social systems to the optimization of health development. 


\section{$5 \quad$ Principle 2: Unfolding}

\subsection{What We Mean by “Unfolding”}

Health development occurs continuously over the lifespan, from conception to death, and is shaped by prior experiences and environmental interactions.

The unfolding principle describes the developmental processes by which expression of a few thousand genes - none of which has a blueprint or roadmap for constituting a viable, living human body - can unfold in an ordered, coherent pattern that has been shaped by the adaptive success of what has worked before. The nonlinear, self-organizing process of development that is made possible by molecule-to-molecule, cell-tocell, tissue-to-tissue, and human-to-human sensing and communication processes means that health development is neither linear, passive, nor static; rather, it is adaptive, self-organizing, and autocatalytic (Davies 2014).

By "adaptive," we mean those biological, behavioral, and cultural differences that are privileged, prioritized, or selected for because of the advantage they imbue on reproductive fitness and success. Adaptive change occurs at multiple levels, from the biochemical and cellular to behavioral change at the level of individuals to environmental change. For some biological systems, such as neural networks, adaptation occurs quite rapidly, enabling real-time responses to acute environmental challenges and acquisition of novel information. However, some biological and behavioral subsystems change slowly responding to gradual shifts in the intensity and quality of ecological exposures. Thus, the adaptation that characterizes health development transpires over multiple time scales enabling response to both fast- and slow-changing variables. The principles of complexity and timing will further elaborate on these features of adaptation.

By "self-organizing," we mean the dynamic nonlinear process of self-assembly and selfperpetuation that emerges through multiple relational coactions between the components of a system and its environments. In the case of human health development, it describes how internally determined structures emerge from a genetic code that is regulated by layers of sensing, signaling, and feedback loops that organize the expression of the code based on chemical self-assembly into variable levels and forms of differentiation. Simple differences in external environments (at the cellular, tissue, organ system, organism, or cultural levels) transform the pathways of development from dull uniformity to autocatalytic diversity of forms and function (Davies 2014).

By "autocatalytic," we mean that health development produces the "fuel" that propels it forward (Henrich 2015). Health development dynamically shapes and is shaped by environmental contexts. Today's health development serves as substrate for the emergence of future health development states. The personenvironmental transactions that unfold during the life course can influence gene regulation of biobehavioral processes through epigenetic changes. Better characterization of this set of mechanisms is helping to explain how physical and social exposures during childhood affect health and disease during adulthood.

The adaptive, self-organizing, autocatalytic processes of unfolding can help to explain how genes and culture have coevolved. According to Henrich (2015), as humans evolved, cultural information and practices began to accumulate and produce cultural adaptations. These new cultural adaptations feed forward and produce significant selection pressure on genes to improve psychological capacities to further acquire, store, process, and organize an array of fitness-enhancing skills and practices. These new adaptive capacities in turn become increasingly available to others in the same cultural group. So as genetic evolution improves the ability of our brains to learn from others, cultural evolution can generate adaptations (i.e., religions, markets, science) that both enhance function and increase the selective pressure on our brains to effectively navigate these increasingly complex cultural forms.

Life history theory suggests that variation in the process of unfolding result in part from the optimization of fitness that occurs during func- 
tionally organized phases of the lifespan. Borrowing from Paul Baltes' lifespan theory (Baltes, Lindenberger, Staudinger 2006), the unfolding principle offers a conceptualization of human health development as having four major functional phases:

(1) Generativity - the preconception, prenatal, and perinatal periods are dedicated to the formation of the organism.

(2) Acquisition of capacity - the early years are dedicated to the acquisition, maturation, and optimization of specific health development capacities.

(3) Maintenance of capacity - the middle years are dedicated to maintaining health development capacities in the face of accumulating risks and ongoing weathering.

(4) Managing decline - the later years are devoted to managing, adjusting, and adapting to functional decline of various body and regulatory systems, even as other aspects of health development such as stress management and positive psychological functioning may improve with age.

Each of these phases is conceptually distinct but can contain overlapping elements, as is the case when an older individual who is mostly in the process of managing decline can also be acquiring new capacities (e.g., learning to play piano at 70). This becomes an adaptive process of maintaining optimal function in the face of declining capacities.

By reflecting evolutionarily defined developmental processes, levels of plasticity, and variation in expression within and across individuals (and within and across biobehavioral systems in the same individual), these four phases help us to see and understand the patterns and coherence of health development. For example, evolution has ensured that the anatomic and metabolic process of bone development in women produces strong bones that enable additional weight carrying associated with pregnancy, until the age of the fourth and fifth decade when menopause emerges. This is an anticipatory developmental process whereby early anticipatory changes prepare the individual to meet future developmental needs. Optimizing bone metabolism and preventing osteoporosis can take several forms, such as physical activity (particularly on hard surfaces), and include different strategies that can be employed during the phases of acquisition and maintenance of bone metabolism and strength and during the management of decline after menopause.

\subsection{Theories and Frameworks Relevant to Unfolding}

The concept of health development as a continuously unfolding adaptive and self-organizing process comprised of distinct yet overlapping functional phases provides a framework for considering how evolutionarily defined stages from life history theory (Stearns 1992; Worthman and Kuzara 2005; Del Giudice et al. 2015), psychological constructs from lifespan human development theory (Baltes 1983; Featherman 1983; Lerner et al. 2010), and sociological constructs from life course sociology (Elder 2000; Mayer 2009; Alwin 2012) can be aligned, compared, and potentially integrated. It also provides a better way of articulating and assessing the alignment between biologically, psychologically, socially, and culturally determined transitions and turning points and understanding how they impact health development over the lifespan (Davies 2014; Henrich 2015) (see Principle 4--Timing). For example, the alignment among the biological processes of menarche, the behavioral maturation of reproduction behaviors, and the culturally created process of mating and marriage has dramatically changed as the age of menarche has declined, the age of marriage has increased, and the introduction of sexualized behavioral stimuli has increased through a variety of different media and information platforms.

\subsection{Implications of the Unfolding Principle}

The adaptive, self-organizing, and autocatalytic way that health development unfolds via com- 
plex sensing, communication, and regulatory processes implies that our basic, clinical, and translational research needs to elucidate how these processes influence the adaptive capacity of individuals and populations. A clearer understanding of how similar self-organizing processes unfold from the cellular level to the cultural level could point to new ways of integrating preventive, health promoting and therapeutic interventions designed to optimize health development by embracing a "cells to society" perspective.

We have proposed that there are four major functional phases of LCHD: generativity, acquisition of capacity, maintenance of capacity, and managing decline. Do these four phases provide a logical staging for all aspects of health development? Are there subphases that need to be articulated to help us better understand the dynamics of health development? To address these questions, we need better measurement of the flow of health development, both continuities and discontinuities, and its variation across and within individuals.

Childhood obesity provides a useful example to illustrate the research implications of the unfolding principle. To evaluate obesity risk, body mass index (BMI) is assessed at a fixed point in time and contrasted with values obtained with population age-sex-specific norms. Newer statistical methods have been developed that enable analysis of intraindividual trajectories to more accurately characterize the pattern of childhood growth and uncover new associations between the functional form of growth trajectories and future obesity and obesity-related comorbidities (Wen et al. 2012). To apply this sort of methodology to health development more broadly requires precise definitions and frequent assessments of health development measures, as well as an understanding of the expected trajectory of health development for the population. These types of assessments are being made available by electronic health records and other digitized health data collected by healthcare organizations, which are a new and ready data source for health development research.

The interaction between various forms of adversity and health development provides another example. Understanding the effects of social adversity and other environmental exposures on the unfolding of health development entails not only connecting the specific types of adversity to different outcomes but also developing a better understanding of the adaptive and self-organizing neuronal and behavioral processes, pathways, and mechanisms by which these outcomes are affected. These include assessing the relationships between neurodevelopmental correlates of socioeconomic adversity and differential structural and functional changes in different regions of the brain (as measured using functional MRIs) and understanding how these changes feed forward and potentially compound or dissipate over time (Caspi et al. 2003; Evans and Schamberg 2009; Hackman and Farah 2009; Noble et al. 2012; Power et al. 2005a, b; Evans et al. 2012).

The short- and long-term effects of adverse in utero exposures on health development are an area of inquiry that is producing a wealth of information and ripe for expansion (Gluckman et al. 2008). This research includes studies regarding epigenetic programming associated with fetal exposure to chemical compounds, environmental toxicants, and smoking (Skinner et al. 2008; Launay et al. 2009; Perera et al. 2009; Martino and Prescott 2011), as well as studies examining the impact of nutritional stresses on metabolic function and future disease ( $\mathrm{Li}$ et al. 2010).

Research on the epigenetic effects of adversity on neurodevelopment has exploded in recent years. Beginning with Meaney's pathbreaking work on the impact of maternal behavior on epigenetic mechanisms that influence gene expression and regulation of the endocrine response to stress (including the glucocorticoid receptor and the corticotropin-releasing factor (CRF) systems that regulate the hypothalamic-pituitary-adrenal axis), there have been a large number of studies examining how different experiences, exposures, and influences can lead to epigenetic alterations affecting a wide range of biobehavioral functions (Meaney 2001, 2010; Turecki and Meaney 2016; Lester et al. 2016). One of the most interesting and challenging areas of epigenetic research concerns the trans-generational transmission of 
exposures and risk through non-germline alterations of genetic information and the persistence of these influences across subsequent generations (Bale 2015).

\section{$6 \quad$ Principle 3: Complexity}

\subsection{What We Mean by "Complexity"}

Health development results from adaptive, multilevel, and reciprocal relations between individuals and their physical, natural, and social environments.

This principle indicates that health development occurs within living systems that are not only adaptive, self-organizing, and autocatalytic but also complex and hierarchically arranged. The topologies of health development phenotypes cannot be fully understood using a traditional biomedical reductionist approach that relies on an analysis and assembly of the parts of subunits. Health development emanates from the hierarchical and relational coactions of the biological and behavioral subsystems and their individual and collective relations with each other and various interconnected external suprasystems (i.e., familial, social, cultural, ecological). Health development phenotypes result from the interplay between the individual and multiple physical, biochemical, psychological, social, and cultural networks that dynamically coact. As in many complex adaptive systems, the directionality of these influences is often context dependent, reciprocal, and influenced by feedback and feedforward influences. On the other hand, small changes in particularly vulnerable parts of a biobehavioral system-or at a specific timesensitive junction in a cascading process of developmental change - can have profound nonlinear effects on the emergence of a capability or health asset or on the overall robustness or fragility of the health development process.

Transactions between different environments can influence gene expression, and gene expression and resultant phenotype can also influence various environments, which will in turn influence additional gene expression. Processes at the molecular level can dynamically coact with each other, as well as with processes at the social and ecological levels, and everywhere in between. These are not simply hierarchical relationships of dependent parts, but are holarchical in the sense that each level is both a part and a whole, nested and hierarchically aligned in the common purpose. In some cases, common purposes are optimizing health development, and in other circumstances, they are aligned to ensure reproductive fitness at the expense of optimal health development (Günther and Folke 1993).

\subsection{Theories and Frameworks Relevant to Complexity}

The complexity principle adds the systemsoriented concepts of complexity, adaptation, emergence, nonlinear change (i.e., small changes can produce large effects and vice versa), and multilevel person-environmental coactions. Key theories, frameworks, and perspectives that support the conceptualization of this principle include general systems theory (von Bertalanffy 1968), chaos theory (Gleick 1987; Lorenz 1993), living systems theory (Miller 1978), humansystem framework (Brody 1973; Seeman 1989), and complex adaptive systems theory (Holland 1998). The systems orientation to health development suggests a holistic, integrated view that there is a need to understand the interdependence of the parts that constitute the whole, which is embedded in its natural and social environments.

\subsection{Implications of the Complexity Principle}

Progress in genomics and network analysis is enabling researchers to interrogate all known gene-disease associations simultaneously and to create a network view of patterns and principles of human disease that would not be apparent by examining genetic associations' one disease at a time (Goh et al. 2007). Extending this approach 
to health development suggests the need to add environmental exposures, or what has been called the "exposome," to analytic models to engender a better understanding of how networks of genes and networks of environments produce health development phenotypes.

The time-honored scientific approach uses the hypothetico-deductive method that derives its cogency from the certainty of deductive inference and the plausibility of abductive inference. Children exposed to the same interacting family, school, and neighborhood environments experience patterns of risk, protective, and healthpromoting influences that emerge out of the complex topography of those personenvironmental interactions. By statistically categorizing and analyzing children by their ethnicity, family income, and family structure, the rich interactions of different environmental factors are often lost (Molenaar et al. 2003). Health development is non-ergodic, meaning that each individual's experiences, environmental interactions, and health development phenotypes are unique and that within a population there is marked heterogeneity. Averaging effects across groups tells us something about population effects, but little about individual effects (Molenaar and Campbell 2009). Furthermore, even though individuals may have different life course experiences, they can experience the same health development phenotype, a phenomenon called equifinality (Cicchetti and Rogosch 1996).

Systems biology and other systems-oriented sciences offer a set of methods that can address the non-ergodic attribute of health development (Huang 2009). Rather than being hypothesis driven, these methods are systems driven and require a research strategy of interrogating the system at the level of the whole (EA Roberts $2015,2012)$. This more complex way of experimenting and generating scientifically valid information bears further discussion and explication. New approaches to study design generation and statistical analysis will be needed to understand how patterns of health development are produced by complex coactions of networks over time. Identifying characteristic health development phenotypes will require nonlinear models that recognize and embrace the complexity of health development. The focus should be on measuring patterns of intraindividual health development, which will require study designs that collect detailed and large volumes of health and environmental information on individuals, forming big health development data resources.

Environments coact with individual constitutional factors to produce health development phenotypes within a person. We have only a vague understanding of the specific environmental variables responsible for these interactions. There is an urgent need to create scientifically useful typologies of environmental variables. This will enable research to better understand how health development signals are transduced from the environment to the individual, altering biobehavioral system configuration and function. Better characterization-and, ultimately, standardization - of environmental variables (the exposome) will accelerate research on how an individual's contexts affect the epigenetic topography and organize what complex systems science might refer to as health development attractor ${ }^{2}$ states. Standardization of concepts and measures enables synthesis and meta-analyses across studies.

\footnotetext{
${ }^{2} \mathrm{An}$ attractor is the end state of a dynamic system as it moves over time. Once the object or data point goes into the basin of attraction, it does not leave unless a strong force is applied. The set of one or more attractors of a dynamic system can be represented visually or graphically as trajectories in state space, where state space represents the multidimensional, abstract space of all possible system behavior. There are four types of possible attractors: fixed points, limit cycles, toroidal attractors, and chaotic (or strange) attractors. Point attractors are regular, terminating in a single point in state space. Cycle attractors are also regular, sometimes oscillating between two or more fixed points or exhibiting a sinusoidal pattern over time. Toroidal attractors are semi-regular, representing coupled rhythms whose ratio of periodicities terminates in an irrational rather than a rational number and appearing in state space as a donut. Chaotic attractors are fully irregular, represented by an aperiodic trajectory in state space that never repeats or settles to a stable pattern, whose basin of attraction is often fractal in shape; see chaos. Regular point and cycle attractors are characteristics of relatively simple systems. Irregular toroidal and chaotic attractors are more characteristics of complex systems.
} 
We have almost no idea at present how to map or represent multilevel emergence, because the transactional nature of health development is not well specified, measured, analyzed, or interpreted. For example, a child exposed to a stressful stimulus that is repeated in unpredictable and unanticipated ways may experience epigenetic changes in neurotransmitter metabolism that cannot be explained just by measuring the stressful stimulus. The developmental timing of these stressful events, their unpredictable repetition, and the temporal rhythms of restorative processes (e.g., sleep) are also at play, which brings us to the next principle.

\section{$7 \quad$ Principle 4: Timing}

\subsection{What We Mean by "Timing"}

Health development is sensitive to the timing and social structuring of environmental exposures and experiences.

Health development is not a linear process in which exposures to environmental stimuli or internalized experiences have equal effects, regardless of when in the life course they occur. Instead, health development results from nonlinear interactions that are both time-specific and time-dependent. There are sensitive periods of a child's life when the impact of certain exposures can be greater than during other periods (Halfon et al. 2014). Time-specific health development pathways refer to biological conditioning that occurs during these sensitive periods, when developing systems are most adaptable and plastic and exogenous and endogenous influences can result in different adaptive responses. In other words, the same exposures can have very different effects depending on when during the life course they occur. Because childhood is a phase of life when biological and behavioral systems are shaped by environmental exposures and social experiences, the timing principle emphasizes the importance of nurturing children when they are most sensitive to these influences (Conti and Heckman 2013). For example, exposure to a rich set of words during the early years of life can greatly improve a child's subsequent language development, with cascading effects on subsequent school performance, health behaviors, and future health status (Hart and Risley 2003).

Time-specific transitions and turning points in health development also result from socially structured pathways that link experiences and exposures in time-influenced ways that create recursive and mutually reinforcing patterns of risk, protection, and promotion. Socially structured pathways have both period-specific and time-dependent (cumulative) characteristics. By arraying risk, protective, and promoting factors into socially constructed and institutionally reinforced pathways that interact with sensitive periods of health development, societies can either support the emergence of positive health development phenotypes or reinforce negative ones. The role, relative dose, duration, and coaction of risk, protective, and promoting factors during formative, maintenance, and declining phases of the life course all influence the slope, shape, and contours of health development trajectories.

Thus, the timing principle summarizes a set of models and constructs that elaborate the importance of the time dimension on health development. There are time-specific pathways that refer to sensitive periods when environmental exposures and experiences can influence health development, and there are time-dependent pathways that refer to the accumulation of repeated exposures to the same environmental stimuli that can result in a weathering process that accelerates aging (Geronimus 2013).

\subsection{Theories and Frameworks Relevant to Timing}

The unfolding principle introduced the concept of functional phases or epochs that organize the historical foundations of health development. The timing principle adds the concepts of timedependent and time-sensitive health development pathways that create periods of vulnerability and robustness, as well as social structuring of environmental exposures and experiences. These con- 
cepts are drawn from several theories, frameworks, and perspectives including developmental origins of health and disease (Gluckman and Hanson 2006a), life course perspective (Elder 2000; Mayer 2009; Alwin 2012), biological embedding (Hertzman and Boyce 2010), chronobiology (Kreitzman and Foster 2004), developmental time (Kuzawa and Thayer 2011), and adaptive developmental plasticity (Gluckman et al. 2009).

\subsection{Implications of the Timing Principle}

Scientists have accumulated tantalizing but as yet limited evidence for time-sensitive health development (Hanson and Gluckman 2014; Hertzman 2012; Boyce and Kobor 2015). Progress in this area has been slow in part because of a lack of data systems that integrate large volumes of biological (especially patterns of gene response and epigenetic changes), clinical (such as electronic health records and biosensors), behavioral (self-report questionnaires), and environmental data. Each of these data sources exists in isolation. What is needed is a new field of health development informatics that is devoted to assembling large, integrated, longitudinal data resources and mining them for novel associations between time, environment, and health development outcomes.

Another challenge is the lack of research that establishes the specific time-dependent pathways by which human health development phenotypes are altered or protected by various internal and external factors. A variety of studies suggest that physical and social environments can alter a person's biology via epigenetic pathways that influence regulation of genetic pathways (Hertzman and Boyce 2010). This "embedding" of experience seems to have its largest impact during specific sensitive periods of development. Why the same experience engenders different outcomes among individuals is one of the great mysteries of health development. More work is needed to elucidate these iterative and dynamic pathways that connect environment to gene regulation to physiological states to environmental impact.

\section{Principle 5: Plasticity}

\subsection{What We Mean by "Plasticity"}

Health development phenotypes are systematically malleable and are enabled and constrained by evolution to enhance adaptability to diverse environments.

The relative plasticity of these phenotypes is responsive to transactions between evolutionarily selected biological and behavioral conditioning and supportive, challenging, and constraining environments. These phenotypes have evolved to provide adaptive capacity, plasticity (i.e., ability of the organism to systematically alter its phenotype in response to environmental challenges, opportunities, barriers, and constraints), and growth potential, which in aggregate refer to the robustness of an individual's health development. Heredity transmits these evolutionary signals through genetic, epigenetic, behavioral, and cultural dimensions (Jablonka and Lamb 2006), which establish the set of health development phenotypes that, depending on environmental circumstances, may or may not be selected and optimized to produce desirable outcomes. At the microlevel, there are a range of strategies to introduce variable types and levels of plasticity to optimize adaptability from the molecular to the behavioral level. At a macro-level, there are social and cultural strategies that organize the phases and life stages of health development into functionally productive entities.

Because developmental plasticity enables the genome to produce a repertoire of possible phenotypes based on environmental cues, an individual begins their life with the capacity to develop in different ways. Different exposures and experiences select and instruct a developmental pathway to respond based on these evolutionary determined strategies. Underlying many forms of plasticity are epigenetic process and resulting cascades of secondary and tertiary responses. Because plasticity can manifest at different levels, behavioral plasticity may be influenced by neural plasticity, and neural plasticity in turn may be influenced by molecular plasticity influenced by epigenetic mechanisms (Bateson and Gluckman 2011). 


\subsection{Theories and Frameworks Relevant to Plasticity}

Evolution both enables and constrains the portfolio of adaptive plastic responses that an individual may experience in response to environmental interactions. Therefore, plasticity is relative, not absolute. Although Darwin's theory of evolution (Darwin 1859; Huxley 1942) laid the foundation for understanding the principle of plasticity, more recent syntheses have expanded our understanding of heredity as including not just genetic change but also epigenetic, behavioral, and cultural phenomena that are transmitted across generations (Waddington 1942; West-Eberhard 2003; Richardson and Boyd 2005; Jablonka and Lamb 2006; Konner 2011; Henrich 2015). These evolutionary forces act at the individual and group level, a perspective known as multilevel selection theory (Okasha 2006).

In some cases, health development outcomes result from the developing individual "predicting" likely future environmental stimuli based on the cues received during sensitive periods of health development. This has been called "predictive adaptive responses" (Gluckman and Hanson 2004). If the developing organism predicts incorrectly-that is, if the environment experienced in the future is not compatible with the cues received during periods of developmental plasticity - health development "mismatches" will occur. This phenomenon can be observed among individuals exposed in utero to maternal malnutrition who later become obese and glucose intolerant, a result of being born into an energyrich environment (Hales and Barker 1992).

\subsection{Implications of the Plasticity Principle}

Evolution has acted on body systems in different ways to encode various types and levels of health development plasticity. The formation of some biological subsystems is tightly controlled by time and gene regulation (e.g., cardiovascular), whereas others seem to have a range of phenotypes that can emerge as a result of interactions with the environment (e.g., stress response, executive function). New models are needed to explain the deep archeology of evolution as it relates to the emergence of health development. Fields like comparative biology can test some of these hypotheses by examining the degree to which specific processes and pathways of health development vary or are preserved across species. For example, patterns of sleep have been selected for and preserved across species in ways that affect how sleep is regulated (Tamaki et al. 2016). Moreover, the success of human civilization has removed much of the selection pressure exerted by mortality, so optimization of specific pathways may be more strongly influenced by culture, behavioral, and epigenetic heredity rather than genetic forces (Enriquez and Gullans 2015). This hypothesis should be tested.

The predictive adaptive response hypothesis has accumulated a substantial amount of animal and human evidence for energy regulation (Gluckman and Hanson 2004a,b). This work should be extended to other domains-for example, behavioral health. Just as childhood obesity may result from mismatches between children's energy regulation and exposure to energy-dense environments, it is possible that the proliferation of childhood disorders like attention deficit hyperactivity disorder, anxiety, and learning disabilities may be a consequence of mismatches between predictive adaptive behavioral responses and the demands children face in terms of executive functioning, emotional functioning, and learning in their home, school, and other environments.

\section{$9 \quad$ Principle 6: Thriving}

\subsection{What We Mean by "Thriving"}

Optimal health development promotes survival, enhances well-being, and protects against disease.

Health development bestows upon the individual resources that have instrumental value, enabling an individual to pursue goals and thrive (Seedhouse 2001; Blaxter 2004; Richman 2004; Forrest 2014). 
It provides assets that individuals employ to pursue the beings and doings (Sen 1999) that characterize each person's lived experiences. Thus, health development phenotypes are instrumental resources that enable individuals to pursue desired goals and live long, flourishing lives.

Health development phenotypes can be considered optimal according to the degree to which they improve the chances of survival of individuals and groups of individuals, the degree to which they support transmission of heritable information to successor generations, and the degree to which they support physical robustness and psychological flourishing (what we term thriving) across time and within the contexts of its environments.

On the other hand, the pathways by which health development phenotypes are formed can be perturbed to create suboptimal states that are precursors to fully formed disease phenotypes. These so-called endophenotypes represent intermediate, subclinical-phased transitions toward a fully manifest phenotypic expression of a disease or disorder (John and Lewis 1966; Gottesman and Gould 2003). For example, the exposure to unpredictable and uncontrollable stressors during sensitive periods of neural development can influence midbrain development and the functional development of attachment relationships, the prefrontal cortex and the functional development of executive function, and the hypothalamic pituitary axis and the regulation of stress responses (Castellanos and Tannock 2002; Boyce 2016). Endophenotypes characterized by anxious attachment, poor impulse control, and hyperactive stress response can impact health behaviors and mental health and contribute to the development of many different chronic diseases including obesity, diabetes, and cardiovascular disease (Duric et al. 2016).

\subsection{Theories and Frameworks Relevant to Thriving}

The principle of health development articulated the singularity of the concepts of health and development. The principle of thriving further clarifies the nature of health development by explicitly characterizing its instrumental nature. That is, health development provides a set of resources that organisms draw on in order to pursue goals, such as surviving, achieving a state of physical robustness and resilience, and psychological flourishing (Seedhouse 2001; Blaxter 2004; Committee on Evaluation of Children's Health 2004; Richman 2004; Forrest 2014). Health development therefore enables the attainment of various beings (states of happiness, life satisfaction, and meaning and purpose) and doings (desired activities that an individual pursues) as individuals pursue their goals over the life course (Sen 1999).

\subsection{Implications of the Thriving Principle}

LCHD recognizes that phenotype is produced by the continuous coactions of at least five factors: genome, epigenome, environment, developmental time, and life course stage. These coactions do not merely produce single outcomes; instead they produce landscapes of possibilities with peaks and valleys shaped by an individual's life history, evolutionary determined possibilities and constraints, and the five-way interaction. Which "attractor" state (i.e., health development phenotype) an individual settles in is the result of this complex, nonlinear process. We know very little about which attractor states are most likely to produce desirable outcomes (i.e., thriving) for which individuals under which circumstances. As we learn more about the interrelationships among these variables, we will begin to forge an ontology that specifies how health development variables interrelate with one another, their subsystems and suprasystem environmental influences, and their consequences. Research is needed that links health development phenotypes, singularly and collectively, that enable individuals with varying personal characteristics and environmental exposures to lead long lives, avoid debilitating disease, and achieve desirable goals and an optimal lived experience. 


\section{Principle 7: Harmony}

\subsection{What We Mean by "Harmony"}

Health development results from the balanced and coherent relations among molecular, physiological, behavioral, cultural, and evolutionary processes.

Genetic modulations that occur in molecular time frames measured in nanoseconds are linked to biochemical modulation measured in milliseconds, homeostatic mechanisms measured in seconds to days, social norms that evolve or years and decades, cultural processes that change from years to centuries, and ecological processes that until recently took millennia. Harmonious synchronization of these processes produces the rhythms and variability that characterize health development. Loss of coordination of these processes results in less robustness of the human system, with resultant negative consequences. For example, the age of menarche has decreased in response to a variety of environmental changes that have resulted in better health and nutrition. In traditional societies, and until about 100 years ago, menarche coincided with maturation of a repertoire of psychological capabilities. Now, menarche precedes this process of psychological maturation, which has also been altered and extended by other cultural and environmental changes (Gluckman and Hanson 2006b). So the adaptive response of menarche to better nutrition and health has led to a temporal and functional uncoupling of biological and psychological capabilities that had previously been harmonized. This has been associated with a range of maladaptive outcomes (Mendle et al. 2007; Ellis and Essex 2007).

\subsection{Theories and Frameworks Relevant to Harmony}

The timing principle introduced the concepts of time dependence, time sensitivity, and social structuring of exposures. The harmony principle extends these concepts by adding the notions of harmonious and balanced relations of the various biological, behavioral, environmental, and cultural systems that an individual is embedded within. Extension of the classic evolutionary modern synthesis - which assumes that phenotypic transitions occur through a series of small steps that result in gradual evolutionary changehas questioned and advanced core assumption about pace of such change. Gradualism has given way in the extended evolutionary synthesis to the notion that evolution can manifest variable rates of change, especially when mutations occur in major regulatory control genes or when developmental process responds to environmental challenges with change in coordinated suites of traits or via nonlinear threshold effects (Laland et al. 2015). Although key theories, frameworks, and models in support of this principle come from chronobiology (Kreitzman and Foster 2004), developmental time (Kuzawa and Thayer 2011), and adaptive developmental plasticity (Gluckman et al. 2009), there is much more theoretical work needed for this principle.

\subsection{Implication of the Harmony Principle}

According to the principles of timing and plasticity, we know that there are periods of the life course when environmental influences can have particularly large effects on health development plasticity. The tremendous plasticity of humans contributes to the robustness and the ordinary magic of child health development (Masten 2001). We need better descriptions and conceptualizations of developmental time as it affects all levels and dimensions of health development and how different time frames nest together to produce coherent developmental pathways and robustness and variability in phenotypic expression. This includes a better understanding of how molecular, physiologic, developmental, historical, cultural, and evolutionary time frames independently and in harmony influence phenotypic variation, through genetic, epigenetic, and yet to be determined mechanisms and pathways. Because developmental time is uneven in its potency, intensity of 
change, and accessibility to environmental influences, there is a great need to better characterize and measure these temporal parameters (Boyce et al. 2012).

\section{Summary}

Health and development are unified into a single construct (health development principle) that adaptively unfolds over the life course (unfolding principle) according to the principles of complex adaptive systems (complexity principle). Change in health development results from time-specific processes (timing principle) that influence biobehavioral systems during sensitive periods when they are most susceptible (plasticity principle), and the balanced alignment of molecular, biological, behavioral, cultural, and evolutionary process (harmony principle) can result in developmental coherence. Health development provides instrumental assets that enable individuals and populations to pursue desired lived experiences (thriving principle).

The Life Course Health Development framework organizes its seven principles into a coherent whole to enable the emergence of a new field of science. The principles should not be viewed as static, independent statements or claims. Instead, they should be considered a set of nodes within a highly interconnected knowledge producing and testing network. We anticipate that these principles will change and evolve as the many fields subsumed by the health development framework themselves mature. Ultimately, we anticipate that the framework will transform into a fully formed theoretical model that enables explanation and prediction of health development phenomena.

\section{References}

Alfred, T., Ben-Shlomo, Y., et al. (2012). A multi-cohort study of polymorphisms in the GH/IGF Axis and physical capability: The HALCyon Programme. PloS One, 7(1), e29883.

Alwin, D. F. (2012). Integrating varieties of life course concepts. The Journals of Gerontology. Series B, Psychological Sciences and Social Sciences, 67(2), 206-220.
Antony, P. M., Balling, R., et al. (2012). From systems biology to systems biomedicine. Current Opinion in Biotechnology, 23(4), 604-608.

Arnesen, E., \& Forsdahl, A. (1985). The Troms $\varnothing$ heart study: Coronary risk factors and their association with living conditions during childhood. Journal of Epidemiology and Community Health, 39(3), 210-214.

Bale, T. L. (2015). Epigenetic and transgenerational reprogramming of brain development. Nature Reviews Neuroscience, 16(6), 332-344.

Baltes, P. B. (1983). Life-span developmental psychology: Observations on history and theory revisited. In R. M. Lerner (Ed.), Developmental Psychology: Historical and philosophical perspectives (pp. 79-111). Hillsdale: Erlbaum.

Baltes, P. B., Lindenberger, U., \& Staudinger, U. M. (2006). Life span theory in developmental psychology. New York: John Wiley \& Sons, Inc..

Baltes, P. B., Reese, H. W., et al. (1980). Life-span Developmental Psychology. Annual Review of Psychology, 31(1), 65-110.

Barker, D. J., Gluckman, P. D., et al. (1993). Fetal nutrition and cardiovascular disease in adult life. Lancet, 341(8850), 938-941.

Barker, D. J., Osmond, C., et al. (1989a). Growth in utero, blood pressure in childhood and adult life, and mortality from cardiovascular disease. BMJ, 298(6673), 564-567.

Barker, D. J., Osmond, C., et al. (1989b). The intrauterine and early postnatal origins of cardiovascular disease and chronic bronchitis. Journal of Epidemiology and Community Health, 43(3), 237-240.

Barker, D. J. P., Thornburg, K. L., et al. (2010). Beyond birthweight: The maternal and placental origins of chronic disease. Journal of Developmental Origins of Health and Disease, 1(6), 360-364.

Bateson, P., \& Gluckman, P. (2011). Plasticity, robustness, development and evolution. Cambridge: Cambridge University Press.

Ben-Shlomo, Y., \& Kuh, D. (2002). A life course approach to chronic disease epidemiology: Conceptual models, empirical challenges and interdisciplinary perspectives. International Journal of Epidemiology, 31(2), 285-293.

Berkman, L. F., \& Syme, S. L. (1979). Social networks, host resistance, and mortality: A nine-year follow-up study of Alameda County residents. American Journal of Epidemiology, 109(2), 186-204.

Blaxter, M. (2004). Health. Cambridge: Polity Press.

Borghol, N., Suderman, M., et al. (2012). Associations with early-life socio-economic position in adult DNA methylation. International Journal of Epidemiology, 41(1), 62-74.

Bornstein, M. H., \& Lamb, M. E. (Eds.). (2005). Developmental science: An advanced textbook (5th ed.). New York: Psychology Press.

Boyce, W. T., \& Kobor, M. S. (2015). Development and the epigenome: the 'synapse' of gene-environment interplay. Developmental science, 18(1), 1-23.

Boyce, W. T. (2016). Differential susceptibility of the developing brain to contextual adversity and stress. 
Neuropsychopharmacology: Official Publication of the American College of Neuropsychopharmacology, 41(1), 142-162.

Boyce, W. T., Sokolowski, M. B., et al. (2012). Toward a new biology of social adversity. Proceedings of the National Academy of Sciences of the United States of America, 109(Suppl 2), 17143-17148.

Brody, H. (1973). The systems view of man: Implications for medicine, science, and ethics. Perspectives in Biology and Medicine, 17, 71-92.

Bronfenbrenner, U. (1976). The ecology of human development: History and perspectives [The ecology of human development: History and perspectives]. Psychologia Wychowawcza 19(5), 537-549.

Bronfenbrenner, U., \& Morris, P. A. (2006). The Bioecological model of human development. In R. M. Lerner \& W. Damon (Eds.), Handbook of child psychology: Theoretical models of human development (Vol. 1, 6th ed., pp. 793-828). Hoboken: John Wiley \& Sons, Inc.

Cairns, R. B., Elder, G. H., et al. (1996). Developmental science: Cambridge studies in social and emotional development. New York: Cambridge University Press.

Caspi, A., Sugden, K., et al. (2003). Influence of life stress on depression: Moderation by a polymorphism in the 5-HTT gene. Science, 301(5631), 386-389.

Cassel, J. (1964). Social science theory as a source of hypotheses in epidemiological research. American Journal of Public Health and the Nation's Health, 54(9), 1482-1488.

Castellanos, F. X., \& Tannock, R. (2002). Neuroscience of attention-deficit/hyperactivity disorder: The search for endophenotypes. Nature Reviews Neuroscience, 3(8), 617-628.

Chen, F., Yang, Y., et al. (2010). Social change and socioeconomic disparities in health over the life course in China a cohort analysis. American Sociological Review, 75(1), 126-150.

Cicchetti, D., \& Cohen, D. J. (1995). Developmental psychopathology: Theory and methods (Vol. 1). Oxford, UK: John Wiley \& Sons.

Cicchetti, D., \& Rogosch, F. A. (1996). Equifinality and multifinality in developmental psychopathology. Development and Psychopathology, 8(04), 597-600.

Clausen, J. A. (1986). The life course: A sociological perspective. Englewood Cliffs: Prentice-Hall.

Cohen, S., \& Herbert, T. B. (1996). Health psychology: Psychological factors and physical disease from the perspective of human psychoneuroimmunology. Annual Review of Psychology, 47, 113-142.

Committee on Evaluation of Children's Health, N. R. C. (2004). Children's health, the Nation's wealth: Assessing and improving child health. Washington, DC: National Academies Press.

Conti, G., \& Heckman, J. J. (2013). The developmental approach to child and adult health. Pediatrics, 131(Suppl 2), S133-S141.

Cunliffe, V. T. (2015). Experience-sensitive epigenetic mechanisms, developmental plasticity, and the bio- logical embedding of chronic disease risk. Wiley Interdisciplinary Reviews: Systems Biology and Medicine, 7(2), 53-71.

Dannefer, D. (1984). The role of the social in life-span developmental psychology, past and future: Rejoinder to Baltes and Nesselroade. American Sociological Review, 49(6), 847-850.

Darwin, C. (1859). On the origin of species by means of natural selection, or the preservation of Favoured races in the struggle for life. London, UK: John Murray.

Davey Smith, G. (2012). Epigenesis for epidemiologists: Does evo-devo have implications for population health research and practice? International Journal of Epidemiology, 41(1), 236-247.

Davies, J. (2014). Life unfolding: How the human body creates itself. Oxford, UK: Oxford University Press.

Davila-Velderrain, J., Martinez-Garcia, J. C., \& AlvarezBuylla, E. R. (2015). Modeling the epigenetic attractors landscape: Toward a post-genomic mechanistic understanding of development. Frontiers in Genetics, 6,160 .

Dawber, T. R., Kannel, W. B., \& Gordon, T. (1974). Coffee and cardiovascular disease: Observations from the Framingham study. New England Journal of Medicine, 291(17), 871-874.

Del Giudice, M., Gangestad, S. W., \& Kaplan, H. S. (2015). Life history theory and evolutionary psychology. The handbook of evolutionary psychology. John Wiley \& Sons, Inc.

Diewald, M., \& Mayer, K. U. (2009). The sociology of the life course and life span psychology: Integrated paradigm or complementing pathways? Advances in Life Course Research, 14(1), 5-14.

Duric, V., Clayton, S., Leong, M. L., \& Yuan, L. L. (2016). Comorbidity factors and brain mechanisms linking chronic stress and systemic illness. Neural Plasticity, 8, 2016.

Egger, G., Liang, G., et al. (2004). Epigenetics in human disease and prospects for epigenetic therapy. Nature, 429(6990), 457-463.

Elder, G. H., Jr. (1995). The life course paradigm: Social change and individual development. In P. Moen, G. H. Elder Jr., \& K. Luscher (Eds.), Examining lives in context: Perspectives on the ecology of human development (pp. 101-139). Washington, DC: American Psychological Association.

Elder, G. H., Jr. (2000). The life course. In E. F. Borgatta \& R. J. V. Montgomery (Eds.), Encyclopedia of sociology (Vol. 3, pp. 1614-1622). New York: Macmillan Reference.

Elder, G. H., \& Shanahan, M. J. (2007). The life course and human development. In Handbook of child psychology. New York: John Wiley \& Sons, Inc.

Elder, G. H., Johnson, M. K., \& Crosnoe, R. (2003). The emergence and development of life course theory. In Handbook of the life course (pp. 3-19). New York: Springer US.

Elks, C. E., Loos, R. J. F., et al. (2012). Adult obesity susceptibility variants are associated with greater childhood weight gain and a faster tempo of growth: The 
1946 British birth cohort study. American Journal of Clinical Nutrition, 95(5), 1150-1156.

Ellis, B. J., \& Essex, M. J. (2007). Family environments, adrenarche, and sexual maturation: A longitudinal test of a life history model. Child Development, 78(6), 1799-1817.

Engel, G. L. (1977). The need for a new medical model: A challenge for biomedicine. Science, 196(4286), 129-136.

Enriquez, J., \& Gullans, S. (2015). Evolving ourselves: How unnatural selection and nonrandom mutation are changing life on earth. New York: Penguin.

Entringer, S., Buss, C., et al. (2012). Fetal programming of body composition, obesity, and metabolic function: The role of intrauterine stress and stress biology. Journal of Nutrition and Metabolism, 2012, 632548.

Essex, M. J., Thomas Boyce, W., et al. (2011). Epigenetic vestiges of early developmental adversity: Childhood stress exposure and DNA methylation in adolescence. Child Development, 84, 58-75.

Evans, G. W., \& Schamberg, M. A. (2009). Childhood poverty, chronic stress, and adult working memory. Proceedings of the National Academy of Sciences of the United States of America, 106(16), 6545-6549.

Evans, G. W., Chen, E., et al. (2012). How poverty gets under the skin: A life course perspective. In V. Maholmes \& R. B. King (Eds.), The Oxford handbook of poverty and child development (pp. 13-100). New York: Oxford University Press.

Featherman, D. L. (1983). Life span perspectives in social science research. In P. B. Baltes \& G. Brim (Eds.), Life-span development and behavior (Vol. 5, pp. 1-57). New York: Academic Press.

Forrest, C. B. (2014). A living systems perspective on health. Medical Hypotheses, 82, 209-214.

Forsdahl, A. (1977). Are poor living conditions in childhood and adolescence an important risk factor for arteriosclerotic heart disease? British Journal of Preventive \& Social Medicine, 31(2), 91-95.

Gatzweiler, F. W., \& Baumüller, H. (2013). Marginality-A framework for analyzing causal complexities of poverty. In J. Braun von \& F. W. Gatzweiler (Eds.), Marginality: Addressing the nexus of poverty, exclusion and ecology (pp. 27-40). Dordrecht: Springer.

Geronimus, A. T. (2013). Deep integration: Letting the epigenome out of the bottle without losing sight of the structural origins of population health. American Journal of Public Health, 103(S1), S56-S63.

Gilbert, S. F., Bosch, T. C., \& Ledón-Rettig, C. (2015 Oct 1). Eco-Evo-Devo: Developmental symbiosis and developmental plasticity as evolutionary agents. Nature Reviews Genetics, 16(10), 611-622.

Gleick, J. (1987). Chaos: Making a new science. New York: Penguin Books.

Gluckman, P. D., \& Hanson, M. A. (2004a). Developmental origins of disease paradigm: A mechanistic and evolutionary perspective. Pediatric Research, 56(3), 311-317.

Gluckman, P. D., \& Hanson, M. A. (2004b). Living with the past: Evolution, development, and patterns of disease. Science, 305(5691), 1733-1736.
Gluckman, P. D., \& Hanson, M. A. (2004c). The developmental origins of the metabolic syndrome. Trends in Endocrinology and Metabolism, 15(4), 183-187.

Gluckman, P. D., \& Hanson, M. A. (2006a). Developmental origins of health and disease. Cambridge, UK: Cambridge University Press.

Gluckman, P. D., \& Hanson, M. A. (2006b). Evolution, development and timing of puberty. Trends in Endocrinology and Metabolism, 17(1), 7-12.

Gluckman, P. D., Hanson, M. A., et al. (2008). Effect of in utero and early-life conditions on adult health and disease. New England Journal of Medicine, 359(1), 61-73.

Gluckman, P. D., Hanson, M. A., et al. (2009). Towards a new developmental synthesis: Adaptive developmental plasticity and human disease. The Lancet, 373(9675), 1654-1657.

Gluckman, P. D., Hanson, M. A., et al. (2010). A conceptual framework for the developmental origins of health and disease. Journal of Developmental Origins of Health and Disease, 1(1), 6-18.

Goh, K. I., Cusick, M. E., et al. (2007). The human disease network. Proceedings of the National Academy of Sciences, 104(21), 8685-8690.

Gottesman, I. I., \& Gould, T. D. (2003). The endophenotype concept in psychiatry: Etymology and strategic intentions. The American Journal of Psychiatry, 160(4), 636-645.

Green, S., Fagan, M., \& Jaeger, J. (2015). Explanatory integration challenges in evolutionary systems biology. Biological Theory, 10(1), 18-35.

Greenberg, G., \& Partridge, T. (2010). Biology, evolution, and psychological development, In The Handbook of life-span development (pp. 115-148). Hoboken: John Wiley \& Sons.

Günther, F., \& Folke, C. (1993 Sep). Characteristics of nested living systems. Journal of Biological Systems, 1(03), 257-274.

Hackman, D. A., \& Farah, M. J. (2009). Socioeconomic status and the developing brain. Trends in Cognitive Sciences, 13(2), 65-73.

Hales, C. N., \& Barker, D. J. P. (1992). Type 2 (noninsulin dependent) diabetes mellitus: The thrifty phenotype hypothesis. Diabetologia, 35, 595-601.

Halfon, N., \& Hochstein, M. (2002). Life course healthdevelopment: An integrated framework for developing health, policy, and research. The Milbank Quarterly, 80(3), 433-479. iii.

Halfon, N., Larson, K., Lu, M., Tullis, E., \& Russ, S. (2014). Lifecourse health development: Past, present and future. Maternal and Child Health Journal, 18(2), 344-365.

Hanson, M. A., \& Gluckman, P. D. (2014). Early developmental conditioning of later health and disease: physiology or pathophysiology? Physiological Reviews, 94(4), 1027-1076.

Hart, B., \& Risley, T. R. (2003). The early catastrophe: The 30 million word gap by age 3 . American Educator, 27(1), 4-9. 
Haynes, S., Feinleib, M., \& Kannel, W. B. (1980). The relationship of psychosocial factors to coronary heart disease in the Framingham Study. III. Eight-year incidence of coronary heart disease. American Journal of Epidemiology, 111(1), 37-58.

Henrich, J. (2015). The secret of our success: how culture is driving human evolution, domesticating our species, and making us smarter. Princeton: Princeton University Press.

Hertzman, C. (1999). The biological embedding of early experience and its effects on health in adulthood. Annals of the New York Academy of Sciences, 896, 85-95.

Hertzman, C. (2012). Putting the concept of biological embedding in historical perspective. Proceedings of the National Academy of Sciences of the United States of America, 109(Suppl 2), 17160-17167.

Hertzman, C., \& Boyce, T. (2010). How experience gets under the skin to create gradients in developmental health. Annual Review of Public Health, 31, 329-347.

Hochberg, Z. E., Feil, R., Constancia, M., Fraga, M., Junien, C., Carel, J. C., Boileau, P., Le Bouc, Y., Deal, C. L., Lillycrop, K., \& Scharfmann, R. (2010). Child health, developmental plasticity, and epigenetic programming. Endocrine Reviews, 32(2), 159-224.

Holland, J. H. (1998). Emergence: From chaos to order. Cambridge, MA: Perseus Books.

Huang, S. (2009). Non-genetic heterogeneity of cells in development: More than just noise. Development, 136(23), 3853-3862.

Huang, S. (2012). The molecular and mathematical basis of Waddington's epigenetic landscape: A framework for post-Darwinian biology? BioEssays: News and Reviews in Molecular, Cellular and Developmental Biology, 34(2), 149-157.

Huxley, J. (1942). Evolution: The modern synthesis. London, UK: Allen \& Unwin.

Jablonka, E., \& Lamb, K. J. (2006). Evolution in four dimensions: Genetic, epigenetic, behavioral, and symbolic variation in the history of life. Cambridge, MA: MIT Press.

John, B., \& Lewis, K. R. (1966). Chromosome variability and geographic distribution in insects. Science, 152(3723), 711-721.

Keating, D. P., \& Hertzman, C. (Eds.). (1999). Developmental health and the wealth of nations: Social, biological, and educational dynamics. New York: Guilford Publications.

Kitano, H. (2002). Systems biology: A brief overview. Science, 295(5560), 1662-1664.

Konner, M. (2011). The evolution of childhood: Relationships, emotion, mind. Cambridge, MA: Belknap Press of Harvard University Press.

Kreitzman, L., \& Foster, R. G. (2004). Rhythms of life: The biological clocks that control the daily lives of every living thing. New Haven: Yale University Press.

Krieger, N. (2001). Theories for social epidemiology in the 21st century: An ecosocial perspective. International Journal of Epidemiology, 30(4), 668-677.

Kuh, D., \& Ben-Shlomo, Y. (2004). Introduction. In D. Kuh \& Y. Ben-Shlomo (Eds.), A life course approach to chronic disease epidemiology (pp. 3-14). New York: Oxford University Press.

Kuh, D., \& Davey Smith, G. (2004). The life course and adult chronic disease: An historical perspective with particular reference to coronary heart disease. In Life course approach to chronic disease epidemiology (pp. 15-37). Oxford University Press.

Kuh, D. J. L., \& Wadsworth, M. E. J. (1993). Physical health status at 36 years in a British national birth cohort. Social Science \& Medicine, 37(7), 905-916.

Kuzawa, C. W., \& Thayer, Z. M. (2011). Timescales of human adaptation: The role of epigenetic processes. Epigenomics, 3(2), 221-234.

Laland, K. N., Uller, T., Feldman, M. W., Sterelny, K., Müller, G. B., Moczek, A., Jablonka, E., \& Odling-Smee, J. (2015). The extended evolutionary synthesis: Its structure, assumptions and predictions. Proceedings. Royal Society B, 282(1813), 20151019.

Launay, J. M., Del Pino, M., et al. (2009). Smoking induces long-lasting effects through a monoamineoxidase epigenetic regulation. PloS One, 4(11), e7959.

Lerner, D. R. M. (1984). On the nature of human plasticity. Cambridge: Cambridge University Press.

Lerner, R. M. (2006). Developmental science, developmental systems, and contemporary theories of human development. In W. Damon \& R. M. Lerner (Eds.), Handbook of child psychology, Vol. 1: Theoretical models of human development (pp. 1-17). Hoboken: Wiley.

Lerner, R. M. (2012). Developmental science: Past, present, and future. International Journal of Developmental Science, 6(1), 29-36.

Lerner, R. M., \& Overton, W. F. (2008). Exemplifying the integrations of the relational developmental system synthesizing theory, research, and application to promote positive development and social justice. Journal of Adolescent Research, 23(3), 245-255.

Lerner, R. M., Overton, W., et al. (2010). Life-span development: Concepts and issues. In The Handbook of lifespan development (pp. 1-29). Hoboken: Wiley.

Lester, B. M., Conradt, E., \& Marsit, C. (2016). Introduction to the special section on epigenetics. Child Development, 87(1), 29-37.

Li, C. C., Maloney, C. A., et al. (2010). Epigenetic programming by maternal nutrition: Shaping future generations. Epigenomics, 2(4), 539-549.

Lillycrop, K. A., \& Burdge, G. C. (2012). Epigenetic mechanisms linking early nutrition to long term health. Best Practice \& Research Clinical Endocrinology \& Metabolism, 26(5), 667-676.

Lieberman, D. (2014). The story of the human body: evolution, health, and disease. New York: Vintage Books.

Lorenz, E. (1993). The essence of chaos. Seattle: University of Washington Press.

Magnusson, D. (1995). Individual development: A holistic, integrated model. In A. Holistic, P. Moen, G. H. Elder Jr., \& K. Luscher (Eds.), Examining lives in context: Perspectives on the ecology of human development (pp. 19-60). Washington, DC: American Psychological Association. 
Maier, S. F., Watkins, L. R., et al. (1994). Psychoneuroimmunology - the Interface between behavior, brain, and immunity. American Psychologist, 49(12), 1004-1017.

Marshall, P. J. (2014). Beyond different levels: embodiment and the developmental system. Frontiers in Psychology, 5, 929.

Marmot, M. G., \& Syme, S. L. (1976). Acculturation and coronary heart disease in Japanese- Americans. American Journal of Epidemiology, 104(3), 225-247.

Marmot, M. G., Adelstein, A. M., et al. (1978a). Changing social-class distribution of heart disease. British Medical Journal, 2(6145), 1109-1112.

Marmot, M. G., Rose, G., et al. (1978b). Employment grade and coronary heart disease in British civil servants. Journal of Epidemiology and Community Health, 32(4), 244-249.

Martino, D., \& Prescott, S. (2011). Epigenetics and prenatal influences on asthma and allergic airways disease. Chest, 139(3), 640-647.

Masten, A. S. (2001). Ordinary magic. Resilience processes in development. The American Psychologist, 56(3), 227-238.

Masters, R. K., Hummer, R. A., et al. (2012). Educational differences in U.S. adult mortality a cohort perspective. American Sociological Review, 77(4), 548-572.

Mayer, K. U. (2009). New Directions in life course research. Annual Review of Sociology, 35, 413-433.

McEwan, B. S. (1998). Protective and damaging effects of stress mediators. New England Journal of Medicine, 338(3), 171-179.

McEwen, B. S. (2012). Brain on stress: How the social environment gets under the skin. Proceedings of the National Academy of Sciences of the United States of America, 109(Suppl 2), 17180-17185.

McMichael, A. J. (1999). Prisoners of the proximate: Loosening the constraints on epidemiology in an age of change. American Journal of Epidemiology, 149(10), 887-897.

McMillen, I. C., \& Robinson, J. S. (2005). Developmental origins of the metabolic syndrome: Prediction, plasticity, and programming. Physiological Reviews, 85(2), 571-633.

Meaney, M. J. (2001). Maternal care, gene expression, and the transmission of individual differences in stress reactivity across generations. Annual Review of Neuroscience, 24, 1161-1192.

Meaney, M. J. (2010). Epigenetics and the biological definition of gene x environment interactions. Child Development, 81(1), 41-79.

Meaney, M. J., Szyf, M., et al. (2007). Epigenetic mechanisms of perinatal programming of hypothalamicpituitary-adrenal function and health. Trends in Molecular Medicine, 13(7), 269-277.

Mendle, J., Turkheimer, E., \& Emery, R. E. (2007). Detrimental psychological outcomes associated with early pubertal timing in adolescent girls. Developmental Review, 27(2), 151-171.

Miller, J. G. (1978). Living systems. New York: McGraw-Hill.
Molenaar, P. C. M., \& Campbell, C. G. (2009). The new person-specific paradigm in psychology. Current Directions in Psychological Science, 18(2), 112-117.

Molenaar, P. C. M., Huizenga, H. M., \& Nesselroade, J. R. (2003). The relationship between the structure of interindividual and intraindividual variability: A theoretical and empirical vindication of developmental systems theory. In Understanding Human Development (pp. 339-360). New York: Springer.

Mortimer, J. T., \& Shanahan, M. J. (2007). Handbook of the life course New York: Springer Science \& Business Media.

Noble, K. G., Houston, S. M., et al. (2012). Neural correlates of socioeconomic status in the developing human brain. Developmental Science, 15(4), 516-527.

Okasha, S. (2006). Evolution and the levels of selection. New York: NY, Oxford University Press.

Overton, W. F. (2007). A coherent Metatheory for dynamic systems: Relational Organicism- Contextualism. Human Development, 50(2-3), 154-159.

Oyama, S. (1985). The ontogeny of information: Developmental systems and evolution. Cambridge, UK: Cambridge University Press.

Perera, F., Tang, W. Y., et al. (2009). Relation of DNA methylation of $5^{\prime}-\mathrm{CpG}$ island of ACSL3 to transplacental exposure to airborne polycyclic aromatic hydrocarbons and childhood asthma. PloS One, 4(2), e4488.

Power, C., Graham, H., et al. (2005a). The contribution of childhood and adult socioeconomic position to adult obesity and smoking behaviour: An international comparison. International Journal of Epidemiology, 34(2), 335-344.

Power, C., Hypponen, E., et al. (2005b). Socioeconomic position in childhood and early adult life and risk of mortality: A prospective study of the mothers of the 1958 British birth cohort. American Journal of Public Health, 95(8), 1396-1402.

Relton, C. L., \& Davey Smith, G. (2012). Is epidemiology ready for epigenetics? International Journal of Epidemiology, 41(1), 5-9.

Roberts, E. A. (2012). Using metalloproteomics to investigate the cellular physiology of copper in hepatocytes. Metallomics, 4(7), 633-640.

Roberts, E. (2015). System-driven research: Legitimate experimental design for biological/biomedical research. Accessed 2017 https://dalspace.library.dal. ca/bitstream/handle/10222/56275/Roberts-Eve-PhDPHIL-May-2015.pdf? sequence $=1 \&$ isAllowed $=y$

Relton, C. L., \& Davey Smith, G. (2012). Is epidemiology ready for epigenetics? International Journal of Epidemiology, 41(1), 5-9.

Repetti, R. L., Robles, T. F., et al. (2011). Allostatic processes in the family. Development and Psychopathology, 23(3), 921-938.

Repetti, R. L., Taylor, S. E., et al. (2002). Risky families: Family social environments and the mental and physical health of offspring. Psychological Bulletin, 128(2), 330-366.

Richman, K. A. (2004). Ethics and the metaphysics of medicine. Cambridge, MA: The MIT Press. 
Richardson, P. J., \& Boyd, R. (2005). Not by genes alone: How culture transformed human evolution. University of Chicago Press.

Sameroff, A. (1975). Transactional models in early social relations. Human Development, 18(1-2), 65-79.

Sameroff, A. (2010). A unified theory of development: A dialectic integration of nature and nurture. Child Development, 81(1), 6-22.

Sapolsky, R. M., Krey, L. C., \& McEWEN, B. R. U. C. E. S. (1985). Prolonged glucocorticoid exposure reduces hippocampal neuron number: Implications for aging. The Journal of Neuroscience, 5(5), 1222-1227.

Schadt, E. E., \& Bjorkegren, J. L. (2012). NEW: Networkenabled wisdom in biology, medicine, and health care. Science Translational Medicine, 4(115), $115 \mathrm{rv} 111$.

Schlotz, W., \& Phillips, D. I. (2009). Fetal origins of mental health: Evidence and mechanisms. Brain, Behavior, and Immunity, 23(7), 905-916.

Seedhouse, D. D. (2001). Health: The foundations for achievement. Hoboken: Wiley.

Seeman, J. (1989). Toward a model of positive health. The American Psychologist, 44(8), 1099-1109.

Seeman, T. E. (1997). Price of adaptation--allostatic load and its health consequences. MacArthur studies of successful aging. Archives of Internal Medicine, 157(19), 2259-2268.

Seeman, T. E., McEwen, B. S., et al. (2001). Allostatic load as a marker of cumulative biological risk: MacArthur studies of successful aging. Proceedings of the National Academy of Sciences, 98(8), 4770-4775.

Sen, A. (1999). Commodities and capabilities. Oxford: Oxford University Press.

Skinner, M. K.,Anway, M. D., et al. (2008). Transgenerational epigenetic programming of the brain transcriptome and anxiety behavior. PloS One, 3(11), e3745.

Spencer, J. P., Thomas, M. S. C., et al. (Eds.). (2009). Toward a unified theory of development: Connectionism and dynamic systems theory re-considered. New York: Oxford University Press.

Starfield, B. (1973). Health services research: A working model. The New England Journal of Medicine, 289(3), 132-136.
Starfield, B., Katz, H., Gabriel, A., et al. (1984). Morbidity in childhood - a longitudinal view. The New England Journal of Medicine, 310(13), 824-829.

Stearns, S. (1992). The evolution of life histories. New York: Oxford.

Stewart, G. T. (1968). Limitations of the germ theory. The Lancet, 291(7551), 1077-1081.

Syme, S. L., \& Berkman, L. F. (1976). Social class, susceptibility and sickness. American Journal of Epidemiology, 104(1), 1-8.

Szyf, M., Weaver, I. C. G., et al. (2005). Maternal programming of steroid receptor expression and phenotype through DNA methylation in the rat. Frontiers in Neuroendocrinology, 26(3-4), 139-162.

Tamaki, M., Bang, J. W., Watanabe, T., \& Sasaki, Y. (2016). Night watch in one brain hemisphere during sleep associated with the first-night effect in humans. Current Biology, 26(9), 1190-1194.

Thayer, Z. M., \& Kuzawa, C. W. (2011). Biological memories of past environments: Epigenetic pathways to health disparities. Epigenetics: Official Journal of the DNA Methylation Society, 6(7), 798-803.

Turecki, G., \& Meaney, M. J. (2016). Effects of the social environment and stress on glucocorticoid receptor gene methylation: A systematic review. Biological Psychiatry, 79(2), 87-96.

von Bertalanffy, L. (1968). General system theory: Foundations, development, application. New York, NY: George Braziller.

Waddington, C. H. (1942). The Epigenotype. Endeavour, $1,18-20$.

Wen, X., Kleinman, K., et al. (2012). Childhood body mass index trajectories: Modeling, characterizing, pairwise correlations and socio-demographic predictors of trajectory characteristics. BMC Medical Research Methodology, 12, 38.

West-Eberhard, M. J. (2003). Developmental plasticity and evolution. New York: Oxford University Press.

Worthman, C. M., \& Kuzara, J. (2005). Life history and the early origins of health differentials. American Journal of Human Biology: The Official Journal of the Human Biology Council, 17(1), 95-112.

Open Access This chapter is licensed under the terms of the Creative Commons Attribution 4.0 International License (http://creativecommons.org/licenses/by/4.0/), which permits use, sharing, adaptation, distribution and reproduction in any medium or format, as long as you give appropriate credit to the original author(s) and the source, provide a link to the Creative Commons license and indicate if changes were made.

The images or other third party material in this chapter are included in the chapter's Creative Commons license, unless indicated otherwise in a credit line to the material. If material is not included in the chapter's Creative Commons license and your intended use is not permitted by statutory regulation or exceeds the permitted use, you will need to obtain permission directly from the copyright holder. 